

\title{
Emulsion polymerization of vinylidene fluoride: Effects of mixing and reaction conditions on the initial rate of polymerization
}

\author{
Ana Carolina M. Ecoscia, Nida Sheibat-othman, Timothy Mckenna, Ana \\ Carolina Mendez Ecoscia, Nida Sheibat-Othman
}

\section{To cite this version:}

Ana Carolina M. Ecoscia, Nida Sheibat-othman, Timothy Mckenna, Ana Carolina Mendez Ecoscia, Nida Sheibat-Othman. Emulsion polymerization of vinylidene fluoride: Effects of mixing and reaction conditions on the initial rate of polymerization. Canadian Journal of Chemical Engineering, 2021, 10.1002/cjce.24145 . hal-03312476

\author{
HAL Id: hal-03312476 \\ https://hal.science/hal-03312476
}

Submitted on 5 Oct 2021

HAL is a multi-disciplinary open access archive for the deposit and dissemination of scientific research documents, whether they are published or not. The documents may come from teaching and research institutions in France or abroad, or from public or private research centers.
L'archive ouverte pluridisciplinaire HAL, est destinée au dépôt et à la diffusion de documents scientifiques de niveau recherche, publiés ou non, émanant des établissements d'enseignement et de recherche français ou étrangers, des laboratoires publics ou privés. 


\title{
Emulsion polymerisation of Vinylidene Fluoride: Effects of Mixing and Reaction Conditions on the Initial Rate of Polymerisation
}

Ana Carolina Mendez Ecoscia ${ }^{1}$, Nida Sheibat-Othman ${ }^{2}$, Timothy F.L. McKenna ${ }^{1, *}$

${ }^{1}$ Université de Lyon, Université Claude Bernard Lyon 1, CPE Lyon, CNRS, UMR 5265, Laboratoire de Chimie, Catalyse, Polymères et Procédés (C2P2) - LCPP group, Villeurbanne, France.

${ }^{2}$ Université de Lyon, Université Claude Bernard Lyon 1, CNRS, UMR 5007, LAGEPP, Villeurbanne, France

Author to whom correspondence should be addressed: timothy.mckenna@univ-lyon1.fr

\begin{abstract}
In order to contribute to a better understanding of the emulsion polymerization of vinylidene fluoride (VDF) an experimental study under conditions of temperature and pressure similar to those found in industrial processes was carried out. It is shown that the initial rate of polymerization is strongly influenced by the agitation of the reactor, with the rate of reaction increasing as the rate of agitation increases. In addition, using a more efficient impeller also increases the polymerisation. It is proposed that this is due to mass transfer limitations. This idea is confirmed by a similar dependence of the average molecular weight on agitation. Experimental data also shows that particles are formed by homogeneous coagulative nucleation. It is proposed that particle nucleation occurs throughout the polymerisation, and that a competition between controlled coagulation and particle generation governs the rate of reaction.
\end{abstract}

\section{INTRODUCTION}

Polyvinylidene fluoride (PVDF) is a polymer made commercially via a free-radical suspension or emulsion polymerisation process. Since the distribution of free radicals, as well as the reactor conditions are not the same in the 2 types of processes, they each produce polymers with a different set of physical propertie. ${ }^{[1]}$ The emulsion polymerisation of vinylidene fluoride (VDF) is the focus of the current paper. Despite the usefulness and industrial importance of this polymer, very few academic studies are available in the open literature on the kinetics and particle formation process during VDF polymerisation. ${ }^{[1]}$ The emulsion polymerisation of PVDF is more complicated than many other emulsion polymerisation processes because the monomer is typically either a gas or a supercritical fluid, and thus much lighter than the continuous phase (water) in the reactor under the polymerisation conditions of interest. In semi-batch processes typical of commercial production, the constant monomer pressure characteristic in industrial 
production means that the reaction rate is exactly equal to the flux of monomer into particles, which is determined by the stirring rate. Therefore, the polymer particles are always "starved", and not necessarily saturated, meaning that mass transfer can potentially limit the rate of polymerisation and eventually the macromolecular properties. These particularities are of course not limited to PVDF homo- and copolymerisations; products such as ethylene-vinyl acetate or others where one or more of the monomers is significantly lighter than the reaction medium will also share certain of these challenges.

The polymerisation of VDF in supercritical carbon dioxide, at temperatures from 50 to $80^{\circ} \mathrm{C}$ and pressures that can exceed $3.05 \times 10^{4} \mathrm{kPa}$ has been discussed in the literature. ${ }^{[2,3,4,5,6]}$ Unfortunately, the difference in reaction and process conditions make it very difficult to extrapolate any of the kinetic interpretations to emulsion polymerisation. Apostolo et al. ${ }^{[7]}$ presented an experimental and modelling study of the copolymerisation of VDF with hexafluoropropylene with a particular focus on the evolution of the molecular weight distribution (MWD). They showed that adding ethyl acetate as a chain transfer agent (CTA) reduced the average molecular weight as expected, but also decreased the degree of long-chain branching. They did not discuss the eventual impact of the CTA on the polymerisation rate. Certain patents $^{[8,9]}$ and a recent paper from our group ${ }^{[10]}$ suggest that some CTA commonly used in the emulsion polymerisation of VDF (in particular ethyl acetate - EA) have a strong impact not only on the average molecular weight, but increasing CTA concentrations can slow down, or totally inhibit the polymerisation reaction.

It is clear that more work needs to be done if we are to better understand key aspects of this industrially important polymer. The objective of this work is to contribute to better understanding of how process parameters like agitation can influence the initial reaction rate, what influences the particle formation process and the polymerisations during the emulsion homopolymerisation of VDF at high pressure; broadly to capture most of the important features that control this system.

\section{EXPERIMENTAL}

Vinylidene fluoride monomer (VDF) was kindly supplied by Arkema (Pierre Bénite, France) and used without further purification. Polymerisation was initiated with Potassium persulfate (99\%, Sigma Aldrich); the emulsion was stabilized by a proprietary anionic surfactant with a critical micelle concentration between 8-12 $\mathrm{g} / \mathrm{L}$ and a parking area $\mathrm{a}_{\mathrm{s}}$ (the surface area occupied by a molecule of surfactant) on the order of $25 \AA^{2}$. Ethyl acetate (ACS grade, Carlo Erba Reagent) was used as chain transfer agent (CTA). Sodium acetate (99\%, Sigma Aldrich) was used as buffer. Parafin wax was used to reduce sticking of the latex on the wall (see reference [1] for a discussion on the role of the wax.) All reagents were employed as received. 


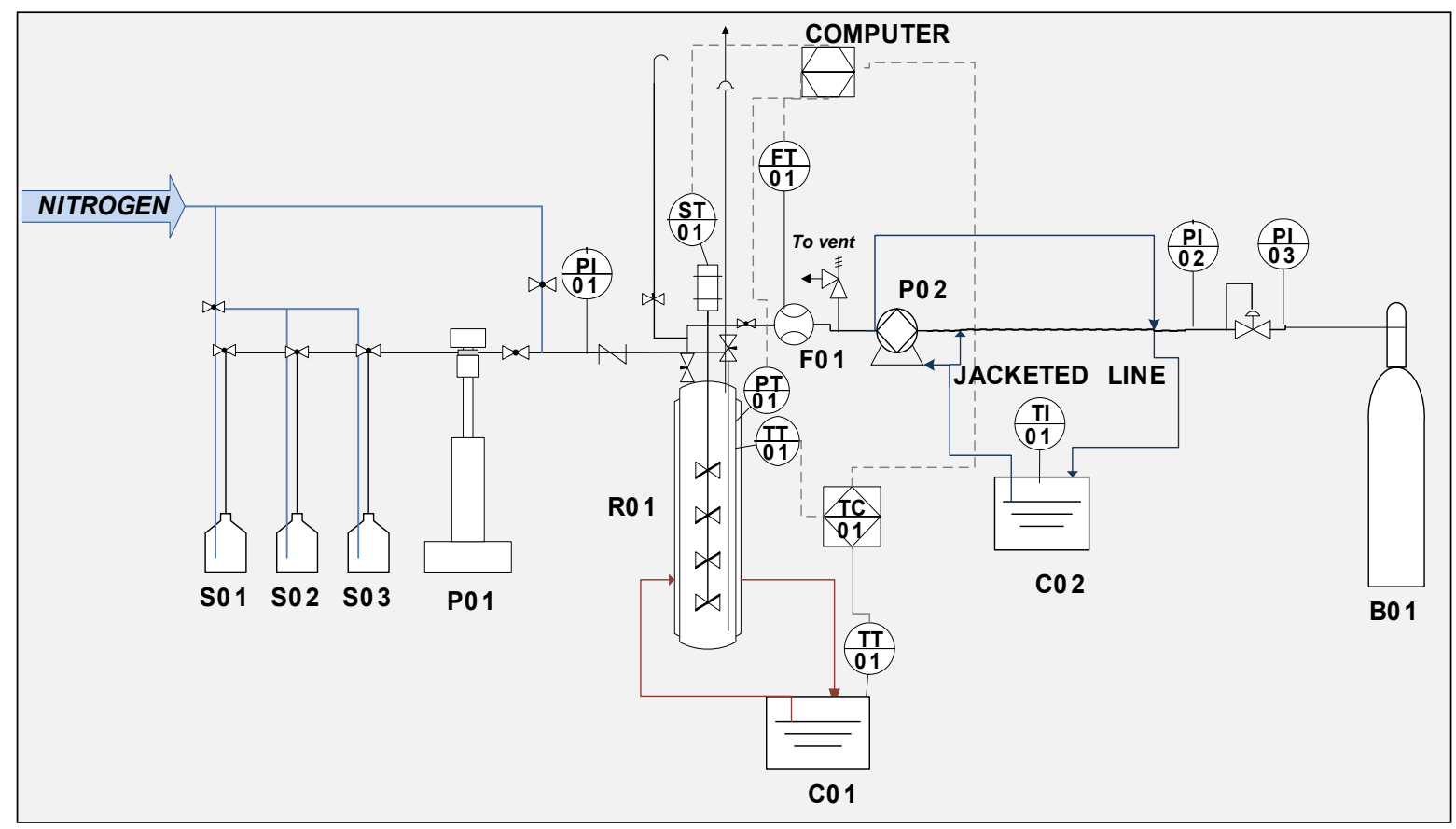

\begin{tabular}{|c|l|}
\hline & \multicolumn{1}{|c|}{ Equipment List } \\
\hline Displayed Text & \multicolumn{1}{c|}{ Description } \\
\hline S01 & CTA container \\
S02 & H2O container \\
\hline S03 & KPS + Buffer container \\
\hline P01 & Syringe pump \\
\hline R01 1 & Reactor \\
\hline P02 & Flowmeter \\
\hline C01 & Dual diaphragm pump \\
\hline C02 & Circulating bath - reactor \\
\hline B01 & Circulating bath - jacketed line \\
\hline
\end{tabular}

Figure 1. Reactor setup for VDF polymerisation.

The Molecular Weight Distribution was measured using the Size Exclusion Chromatography, equipped with three porous columns - two columns of $1000 \AA$ and one column of $30 \AA$ - of Polyester copolymer (Gram columns, PSS). A mixture of Dimethyl sulfoxide (DMSO) with sodium nitrate (NaNO3) previously filtered was used as solvent. The latex samples were first dried and then solutions of around $5 \mathrm{mg} / \mathrm{mL}$ were prepared and maintained at $55{ }^{\circ} \mathrm{C}$ to ensure the complete dissolution. When the samples were completely dissolved, solutions were filtered using nylon filter of $0.45 \mu \mathrm{m}$ porous size. The retention time and the molecular mass of the injected PVDF were obtained using the PMMA calibration. The calibration curve was constructed using three samples of PMMA, the minimum molecular weight was $831 \mathrm{Da}$ and the maximum was $1,430,000 \mathrm{Da}$ 
A schema of the reactor set-up is shown in Figure 1. Polymerizations were performed in an unbaffled $4 \mathrm{~L}$ jacketed 316 Stainless steel autoclave described elsewhere [10,11]. 2 dip tubes (one to feed liquid components, and one to house the thermocouple) serve to interrupt the internal flow. The internal reactor diameter is $0.101 \mathrm{~m}$. The bottom of the reactor has a truncated cone form of height $0.009 \mathrm{~m}$ and a diameter varying from 0.08 to $0.014 \mathrm{~m}$. The inlet and outlet temperatures of the jacket were measured and used to follow the rate of polymerization by calorimetry. ${ }^{[11]}$ The reactor temperature was regulated by a Proportional Integral Derivative (PID) controller. The volume of liquid in the reactor varies between $2 \times 10^{-3}$ (initial volume of water) and $2.5 \times 10^{-3} \mathrm{~m}^{-3}$ (final volume of latex reported) during the reaction. Note that the objective of the current paper is to demonstrate the impact that mass transfer limitations can have on the polymerization rate and polymer properties when the monomer is significantly lighter than the continuous phase.

Deionized water, surfactant, and wax were added to the reactor in an initial step. The feed line was then shut and the reactor heated to increase the temperature to $83^{\circ} \mathrm{C}$ under agitation. During the heating step, the reactor was peruged with nitrogen to remove residual oxygen. CTA and monomer were introduced in subsequent steps with a syringe pump (500HL Syringe Pump, Isco). VDF was fed into the reactor via a refridgerated feedline, and entered the feed pump at $10-20^{\circ} \mathrm{C}$. A Coriolis mass flowmeter (Optimass 3000, Khrone) was used to monitor the inlet feed rate, which also provided a redundant measure of the reaction rate.

The rate of agitation was reduced at the end of the polymerization, and the reactor was cooled by reducing the temperature in the external jacket. The residual VDF was removed by gentle degassing. The final latex was removed via a valve at the bottom of the reactor under nitrogen purge. Reference values of the levels of reactive components used in the runs are based non the range given in Table 1: $8800 \mathrm{kPa}(88$ bars) VDF; $w a x=2.4 \mathrm{~g} / \mathrm{L} ; \mathrm{EA}=3.3 \mathrm{~g} / \mathrm{L} ;$ Salt $=0.06 \mathrm{~g} / \mathrm{L}$; surfactant $1.5 \mathrm{~g} / \mathrm{L}$; and KPS $=0.09 \mathrm{~g} / \mathrm{L}$. The reference agitation speed was set at $550 \mathrm{rpm}$ or 400 rpm, depending on the agitation system, as described below. All polymerisations will use these reference values unless otherwise stated. We will look at the impact of varying the EA, surfactant, KPS, stirring rate and impeller type in the following sections.

Table 1. Range of literature values for PVDF emulsion polymerisation formulations.

\begin{tabular}{llc}
\hline \multicolumn{1}{c}{ Parameter } & \multicolumn{1}{c}{ Value } & Reference \\
\hline Maximum VDF Pressure & $8800 \mathrm{KPa}(88$ bars $)$ & {$[12]$} \\
\hline Parafin wax & $0-6 \mathrm{~g} / \mathrm{L}$ & {$[13,14,15,16,17]$} \\
\hline Temperature & $80-85^{\circ} \mathrm{C}$ & {$[12,13,18]$} \\
\hline CTA - Ethyl acetate & $1.2-24 \mathrm{~g} / \mathrm{L}$ & $\begin{array}{c}{[12 \text { Erreur } !} \\
\text { Signet non } \\
\text { défini., } 19]\end{array}$ \\
\hline KPS & & {$[20]$} \\
\hline
\end{tabular}


Surfactant (anionic, proprietary) $\quad<<\mathrm{CMC}$

Note: all concentrations are given in grams of active material per litre of pure water.

\section{RESULTS AND DISCUSSION}

\subsection{Influence of Agitation on the Reaction}

As discussed by Mendez Ecoscia et al. ${ }^{[1]}$, it is expected that the agitation can have an impact not only only latex coagulation, but also on the reaction rate in polymerisations where the monomer is significantly lighter than the continuous reaction as is the case here. To this end we investigated the influence of 2 different agitation systems and the agitation speed on the polymerisation rate. These are shown in Figure 2. With the initial Setup S1, the mixing system consists of a central shaft and 4 pitched six-blade turbine impellers $\left(45^{\circ}\right)$ with a $5 \mathrm{~cm}$ diameter; one at the bottom of the shaft $8 \mathrm{~cm}$ from the reactor bottom and the other 3 impellers at $8 \mathrm{~cm}$ intervals above. Agitator setup S2 is similar, but the $45^{\circ}$ pitched $5 \mathrm{~cm}$ impeller at the bottom was replaced by a 4-blade A315 hydrofoil with a diameter of $8 \mathrm{~cm}$, while keeping the 3 of the previous turbines at $8 \mathrm{~cm}$ intervals above it. Given that we are working at surfactant concentrations well below the CMC it was important to use a low shear agitator like the hydrofoil, in order to avoid shear-induced particle coagulation. ${ }^{[21]}$

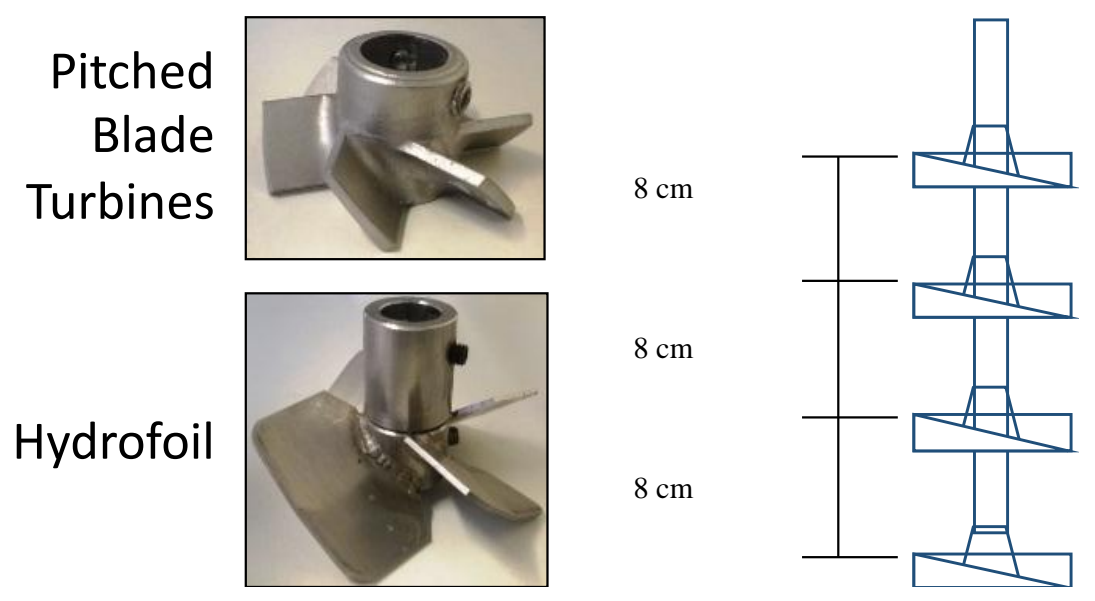

Figure 2. Different impellers considered in the current work, and configuration of the agitation system. S1 consisted of 4 pitched blades arranged as shown. With S2 the bottom pitched blade was replaced by the hydrofoil.

Several batch polymerisations were run to explore the impact of the agitation system and speed on the polymerisation rate and the reactor temperature. The results are shown in Figure 3 for the original S1 configuration, where it can be seen that the agitation rate has a strong impact on the rate of batch polymerisation (Figure 3a), and on the ability to control the reactor temperature (Figure 3c). At the fastest agitation speed, $650 \mathrm{rpm}$, the rate of polymerisation $\left(R_{\mathrm{p}}\right)$ was significantly higher than for the other runs. Under these conditions, $R_{\mathrm{p}}$ increases very rapidly, 
reaching a maximum approximately 18 minutes after the beginning of the reaction. The subsequent decrease in the reaction rate is due to the disappearance of monomer in the batch mode as shown by the pressure drop (Figure $3 \mathrm{~b}$ ). The reactor temperature also rises very quickly and becomes controllable again only when $R_{\mathrm{p}}$ diminishes. Therefore, despite the fact that the reactor side heat transfer coefficient is expected to be higher under higher agitation speeds (see Figure 5 below), it is difficult to control the reactor temperature at agitation rates much higher than $600 \mathrm{rpm}$. Finally, the particle size distributions from these experiments (Figure 3d) show no signs of noticeable agglomeration at the different stirring rates.

a)

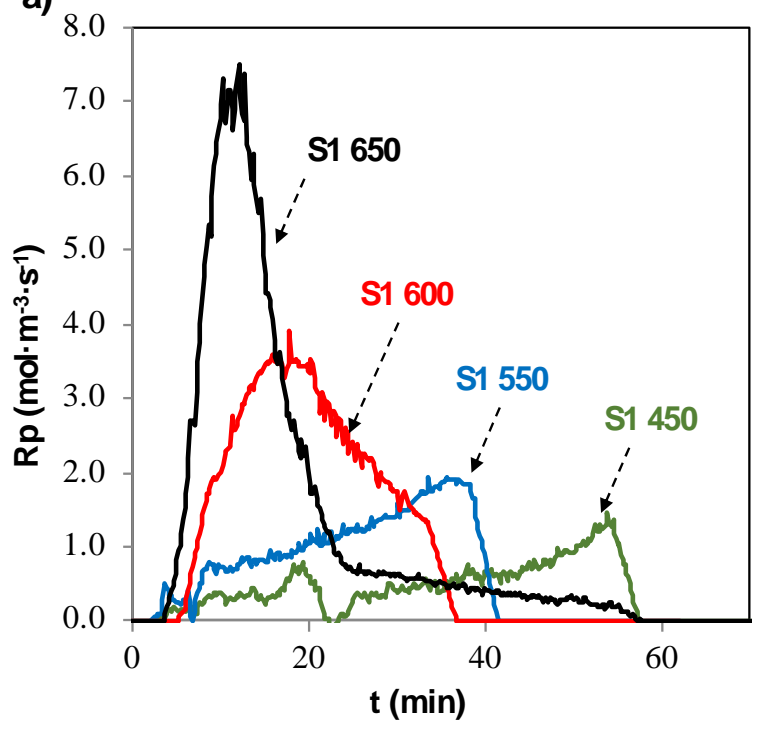





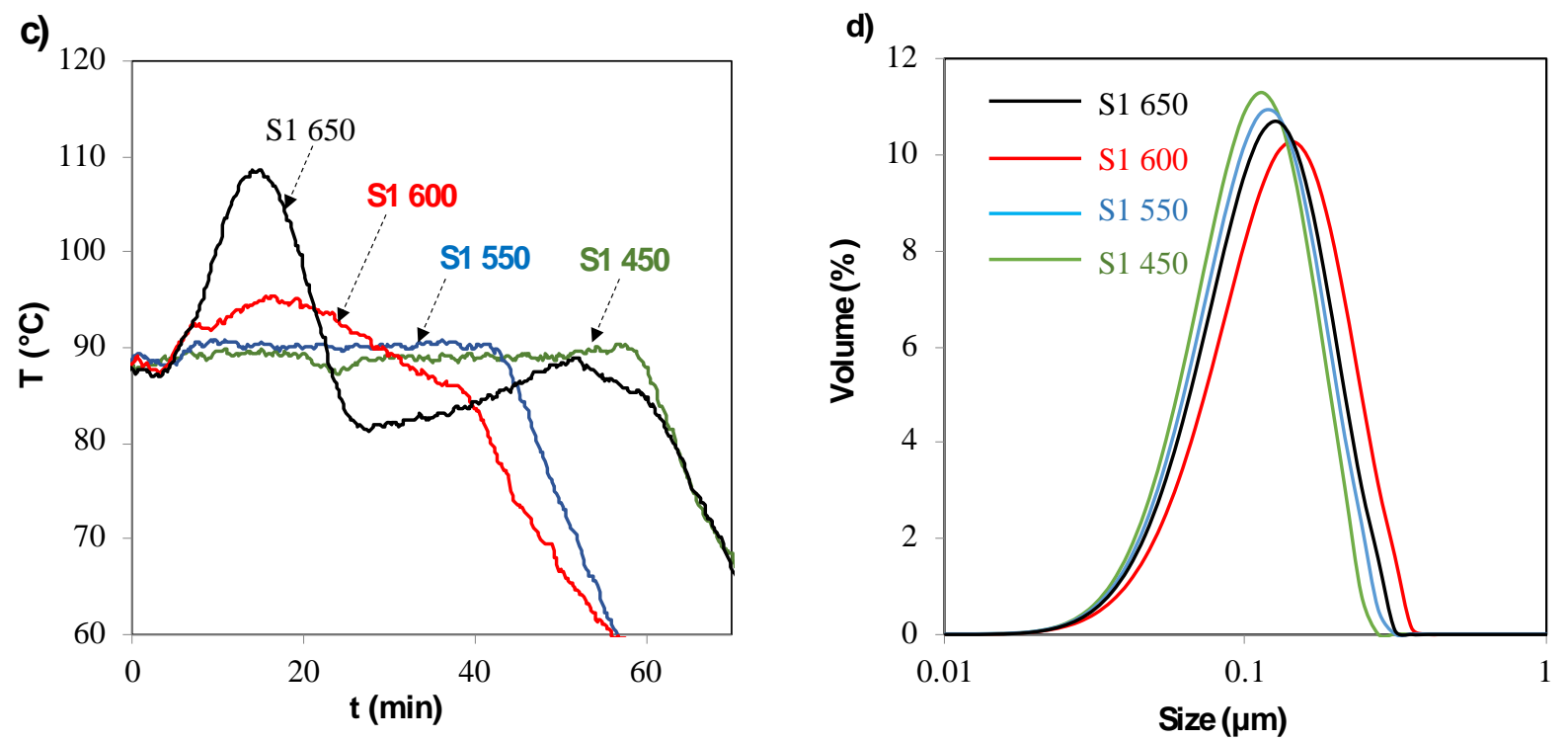

Figure 3. Impact of the agitation speed of batch polymerisations stirred with agitation setup S1 on: (a) the on the rate of polymerisation estimated by pressure drop in the reactor; (b) the pressure; (c) reactor temperature; (d) the particle size distribution. Set point temperature $85^{\circ} \mathrm{C}$, initial pressure $8300 \mathrm{kPa}$ (83 bars). Experimental conditions: $1.5 \mathrm{~g} / \mathrm{L}$ of surfactant, $0.32 \mathrm{~g} / \mathrm{L}$ of KPS, $0.06 \mathrm{~g} / \mathrm{L}$ of buffer.

a)

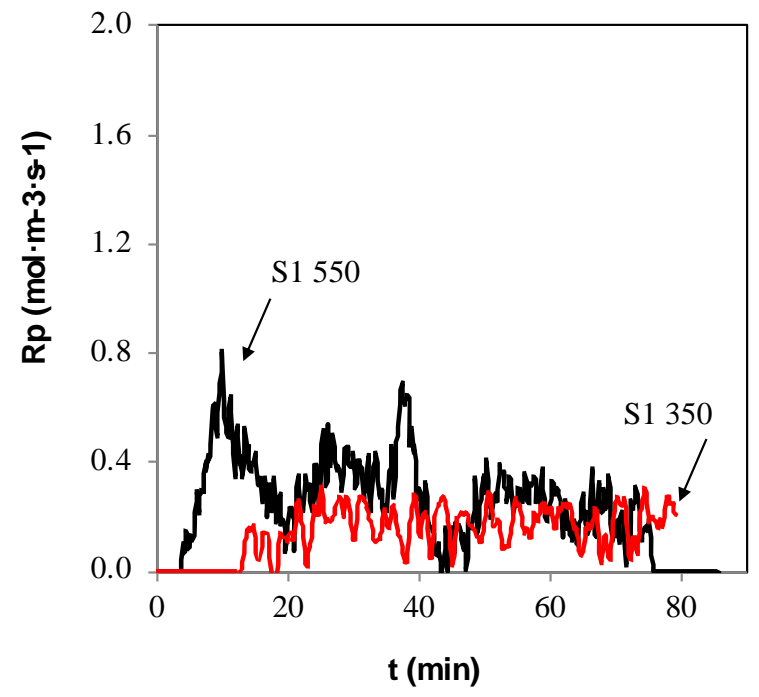

b)

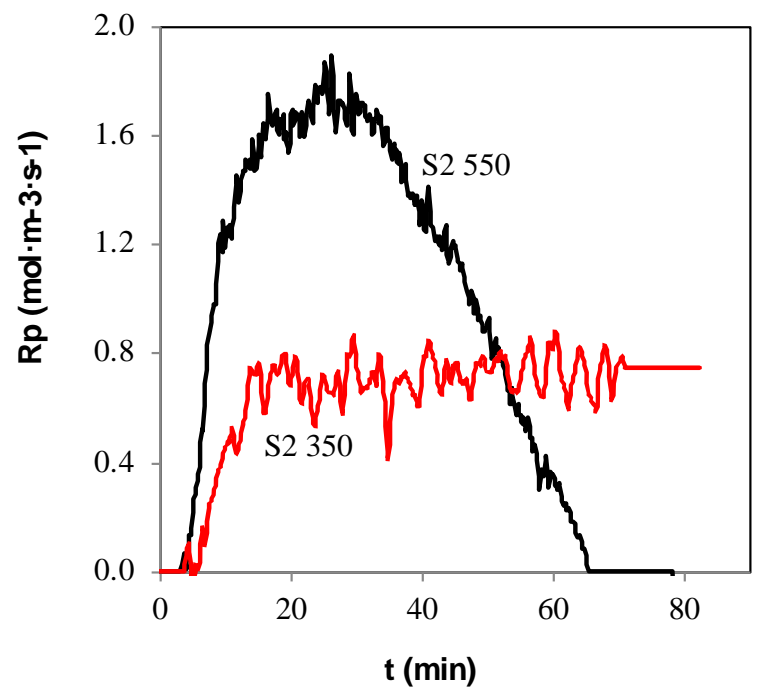


c)

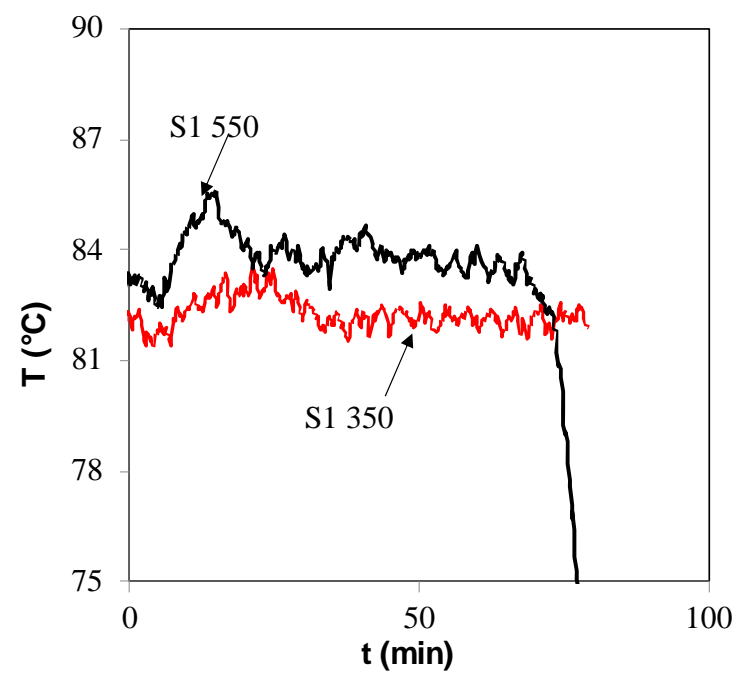

d)



Figure 4. Impact of the agitation speed on the rate of polymerisation in batch for setups S1 (a) and S2 (b) respectively, and on the measured reactor temperature for S1(c) and S2 (d) respectively. Set point temperature $83^{\circ} \mathrm{C}$. Experimental conditions: $1.5 \mathrm{~g} / \mathrm{L}$ of surfactant, 0.09 $\mathrm{g} / \mathrm{L}$ of KPS.

Figure 4 shows that using the hydrofoil (S2) leads to significantly higher rates than when S1 was used. It should be noted that different levels of initiator were used in the experiments shown in Figures 3 and 4, but it is reasonable that the lower initiator concentrations used in Figure 4 would lead to lower polymerisation rates, and that the general trends in terms of how S1 and S2 impact the polymerisation can translate from one figure to the next.

Once again, it is important to pay attention to the control of the reactor temperature. The setpoint for these experiments was $83^{\circ} \mathrm{C}$, and for high polymerisation rates, and in particular at 550 rpm, Figure $4 \mathrm{c}$ and Figure $4 \mathrm{~d}$ show that small temperature excursions are observed at the beginning of the reaction for both $\mathrm{S} 1$ and $\mathrm{S} 2$. For S2, the reaction rate is at least twice as high at peak values, but the improved quality of mixing implies that the heat transfer coefficient is much better for S2 than for S1. The approach described by Mendez-Ecoscia et al. ${ }^{[1]}$ was employed to estimate the lumped heat exchange coefficient $U$ for these experiments, and it can be seen from Figure 5 that $\mathrm{S} 2$ at $550 \mathrm{rpm}$ offers much higher values of $U$ than $\mathrm{S} 1$ at $550 \mathrm{rpm}$ (but at $350 \mathrm{rpm}$, $U$ is similar for both $\mathrm{S} 1$ and $\mathrm{S} 2$ ). 


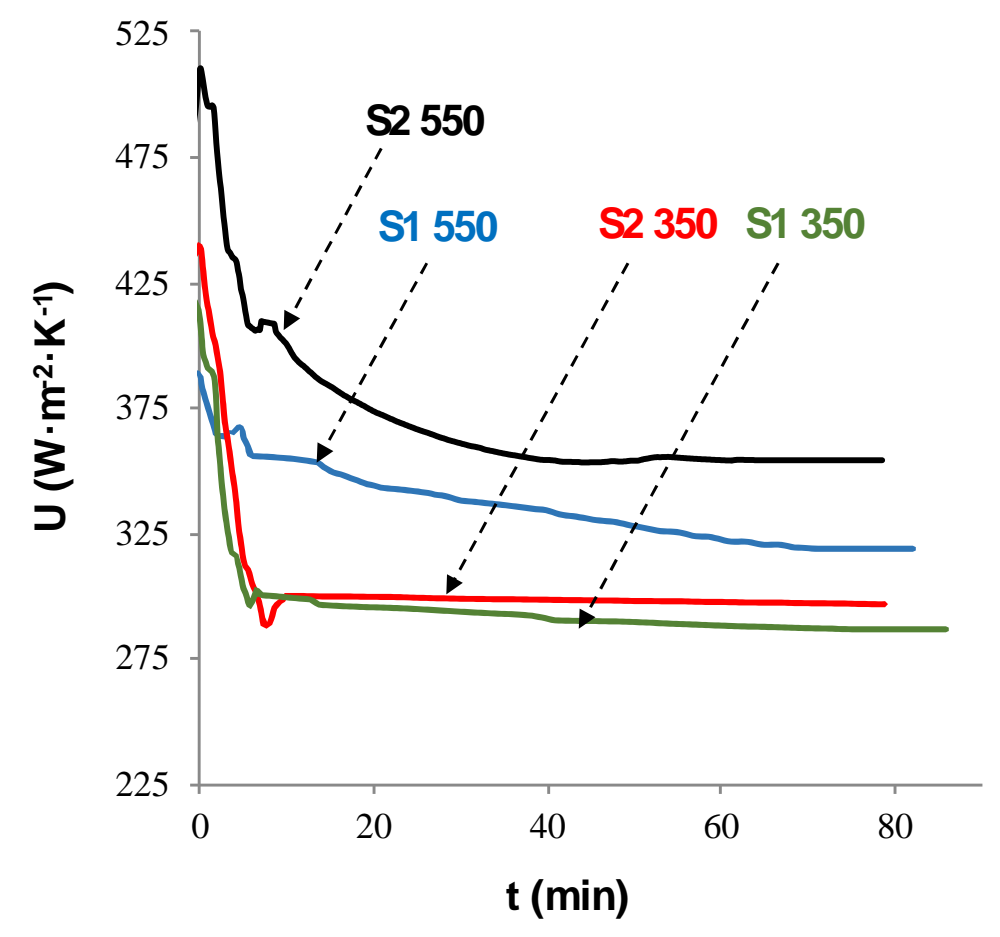

Figure 5. Overall heat transfer coefficient $\mathrm{U}$ for the different agitation setups and stirring rates for the experiments shown in Figure 4.

There is clearly a trade-off between enhanced polymerisations rates and the ability to remove the heat due to the high reaction rate. The higher rates observed at higher stirring speeds are most likely attributable to enhanced mass transfer from monomer "bubbles" to the aqueous phase. If the aqueous concentration of VDF is below its saturation limit, and consequently the concentration of VDF in particles is lower than its saturation value, it is possible that higher stirring rates will lead to an increase in these quantities.

In order to understand how the agitation rate impacted mass transfer during the polymerizations, a series of measurements were realized, based on the dynamic technique reported by Chaudhari et al. ${ }^{[22]}$, to evaluate the gas-liquid mass transfer coefficient $k_{L} a$ for agitator $\mathrm{S} 2$ at $83^{\circ} \mathrm{C}$. Specifically, in absence of chemical reaction, we assumed that the variation of the monomer absorption into the aqueous phase and polymer particles is directly related to the evolution of the pressure as a function of time. The general operating protocol consists in the following steps:

1. A charge composed of deionized water (or PVDF latex at a given solids content) was added into the reactor and the agitation was set on. The PVDF latex was produced in batch mode and has a crystallinity of approximately $48 \mathrm{wt} \%$.

2. The liquid was degassed with nitrogen until the desired temperature was reached.

3. Monomer was added into the reactor via the diaphragm pump, and the inlet mass was monitored. 


\section{Injection of monomer was stopped.}

5. The reactor pressure was measured every 10 seconds until equilibrium is reached

6. Steps 3-5 were repeated.

Figure 6 shows a typical profile of the pressure versus time. Note that pressure drop can only be seen clearly and reproducibly when the pressure is lower than $4000 \mathrm{kPa}$ (40 bars), so all data treatments were carried out at a pressure of $2500 \mathrm{kPa}$ ( $25 \mathrm{bars}$ ). In principle, the mass transfer coefficient should be independent of the pressure, since the impact of the pressure on the flux from the gas phase bubbles to the liquid should be accounted for in the driving force shown in Equation (1):

$$
F_{A}=k_{L} S\left(C_{A, I}-C_{A, L}\right)
$$

where $F_{A}$ is total diffusive flux of the component A (here gas) out of the "bubbles", $k_{L}$ is the liquid mass transfer coefficient of $\mathrm{A}, S$ is the mass transfer area, $C_{A, I}$ is the interfacial concentration, and $C_{A, \mathrm{~L}}$ is the bulk concentration.

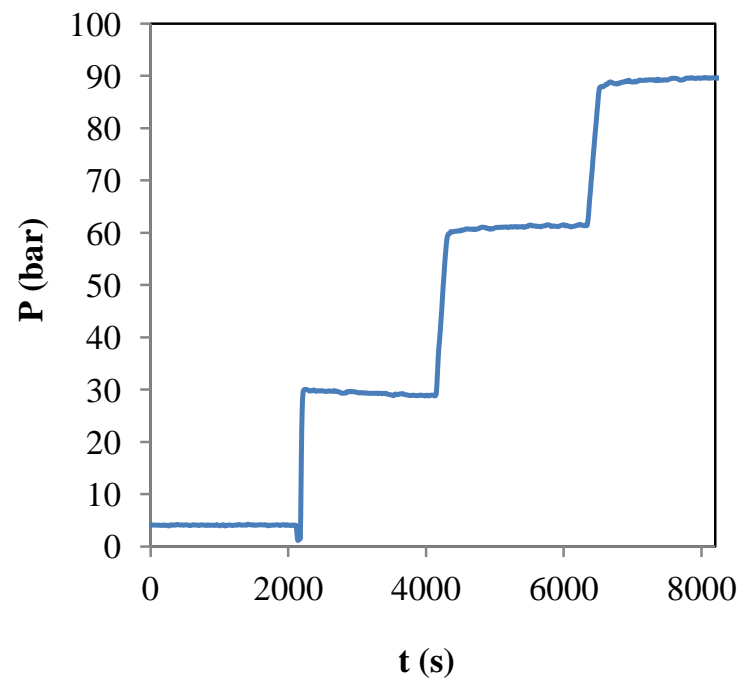

Figure 6. Example of raw data: Evolution of the reactor pressure at $83{ }^{\circ} \mathrm{C}$, obtained at $400 \mathrm{rpm}$ and $13,8 \%$ wt of solids content.

Figure $7 \mathrm{a}$ shows an example of the monomer pressure drop during the batch absorption. The following assumptions were made in order to estimate the mass transfer coefficients: (i) the volumes of the liquid and gas phases remain invariable during the experiments; (ii) the monomer heat transfer rate is faster than monomer mass transport, (iii) pressure variation is due to gas absorption (i.e. $F_{\mathrm{A}}=-\frac{V_{\mathrm{g}}}{R T} \frac{\mathrm{d} P}{\mathrm{~d} t}$ ). Then, the mass balance of the gas inside the reactor can be expressed as ${ }^{[23,24,25]}$ : 


$$
\begin{gathered}
\ln \left[\frac{P_{\mathrm{m}}-P_{0}}{(1+C)\left[P(t)-P_{0}\right]-C\left[P_{\mathrm{m}}-P_{0}\right]}\right]=k_{L} a\left(1+\frac{1}{C}\right) t \\
\text { with } C=\frac{P_{\mathrm{f}, \mathrm{eq}}-P_{0}}{P_{m}-P_{\mathrm{f}, \mathrm{eq}}}=\frac{H_{\mathrm{e}} V_{\mathrm{g}}}{V_{\mathrm{L}} R T}
\end{gathered}
$$

where $a\left(\mathrm{~m}^{2} \mathrm{~m}^{-3}\right)$ is the mass transfer area per unit volume, $P_{0}$ is the initial pressure baseline (registered just before adding the monomer) resulting from the mass of water in the vapor phase and remaining nitrogen, $P(t)$ is the pressure at any given time $\mathrm{t}, P_{m}$ is the pressure at a given time $\mathrm{t}$ and $P_{\mathrm{f} \text {,eq }}$ is the final pressure obtained when the mass transfer equilibrium is reached, and $H_{e}$ is the Henry coefficient.

a)

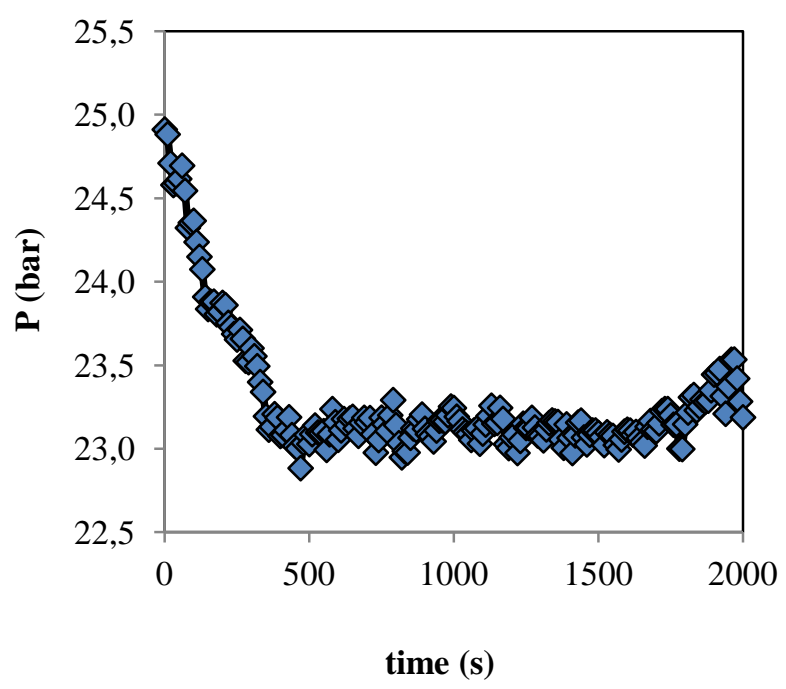

b)

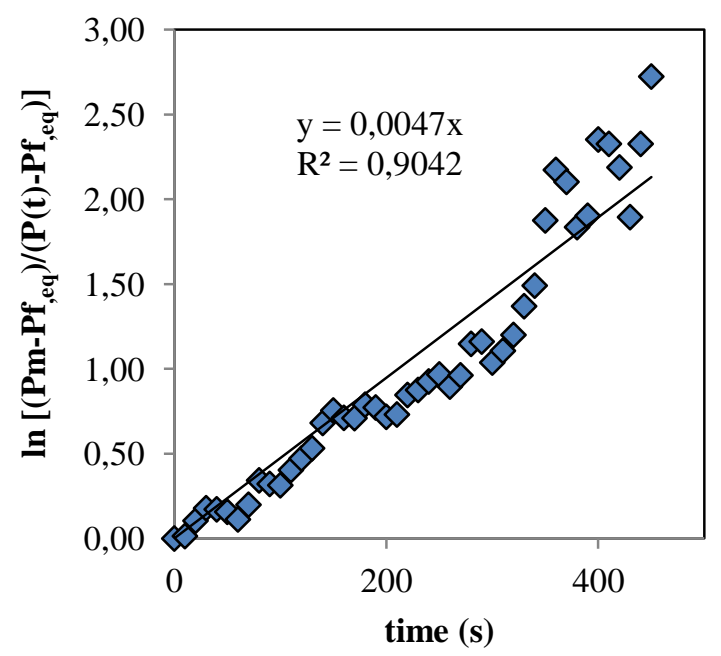

Figure 7. Example of a) monomer pressure drop during batch absorption and b) data analysis, collected at $550 \mathrm{rpm}$ and $13.8 \% \mathrm{wt}$ of solids content.

As shown in Figure 7b, a linear fit to the variation slope of $\ln \left[\frac{P_{\mathrm{m}}-P_{\mathrm{f}, \mathrm{eq}}}{P(t)-P_{\mathrm{f}, \mathrm{eq}}}\right]$ versus time can be used to compute the mass transport coefficient since:

$$
\text { slope }=k_{L} a\left[\frac{P_{\mathrm{m}}-P_{0}}{P_{\mathrm{f}, \mathrm{eq}}-P_{0}}\right]
$$

Figure 8a shows the influence of the agitation on the monomer mass transport coefficient, and the characteristic mass transfer time is shown in Figure 8b. As expected the mass transport coefficient increases as the rate of agitation increases, as a consequence of the bigger generated area of monomer "bubbles". The evolution of the mass transfer coefficient with agitation speed shows similar tendencies to other studies, for instance in a Fischer-Tropsch system. ${ }^{25}$ Typically, 
reactions were carried out at 400 (for agitator S2) in semi-batch mode and $550 \mathrm{rpm}$ (for agitator $\mathrm{S} 1$ ) in batch mode. At these stirring speeds we can see that at 2-3 minutes are required to attain the monomer mass transfer equilibrium at 30 bar, whereas at lower agitation rates, the characteristic mass transfer time is quite slow.

a)

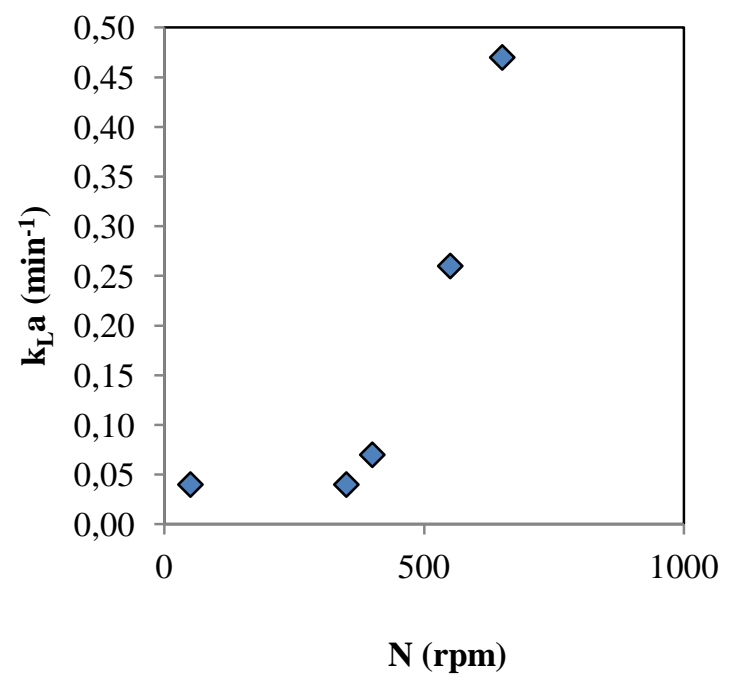

b)

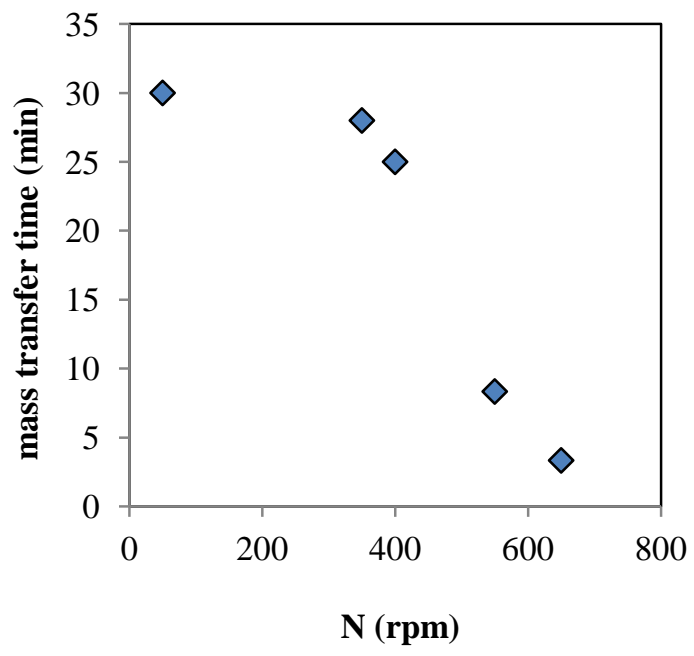

Figure 8. (a) Gas (supercritical fluid)-liquid mass transfer coefficient $\mathrm{k}_{\mathrm{L}} \mathrm{a}$ as a function of stirring speed for agitator S1. (b) the equivalent mass transfer time at $83{ }^{\circ} \mathrm{C}$. Solid content $13.8 \mathrm{wt} \%$.

If one considers the evolution of the weight average molecular weight $\left(M_{\mathrm{w}}\right)$ seen in Figure 9 , the almost linear dependence of $M_{\mathrm{w}}$ on the rate of agitation, coupled with the $\mathrm{k}_{\mathrm{L}}$ a data in Erreur ! Source du renvoi introuvable. strongly suggests that at lower stirring speeds the particles are in fact starved of monomer. The only difference between these experiments is the stirring speed and a drift in the temperature of a few degrees. The stirring speed itself should not directly influence the molecular weight of course. And while the temperature might be a factor, higher temperatures noted at the higher stirring speeds would decrease, not increase, the molecular weight. Particle size information cannot be reported here, but we can affirm that as was seen for the batch experiments (Figure 3d) no agglomeration was detected in any of these experiments. There is no evidence that a change in diameter occurred that could provoke large enough changes in the average number of radicals per particle to explain the observed differences in. The only reasonable explanation for the higher molecular weight is an increase in the monomer concentration at higher agitation rates (explained nicely by the higher mass transfer rates shown above). 


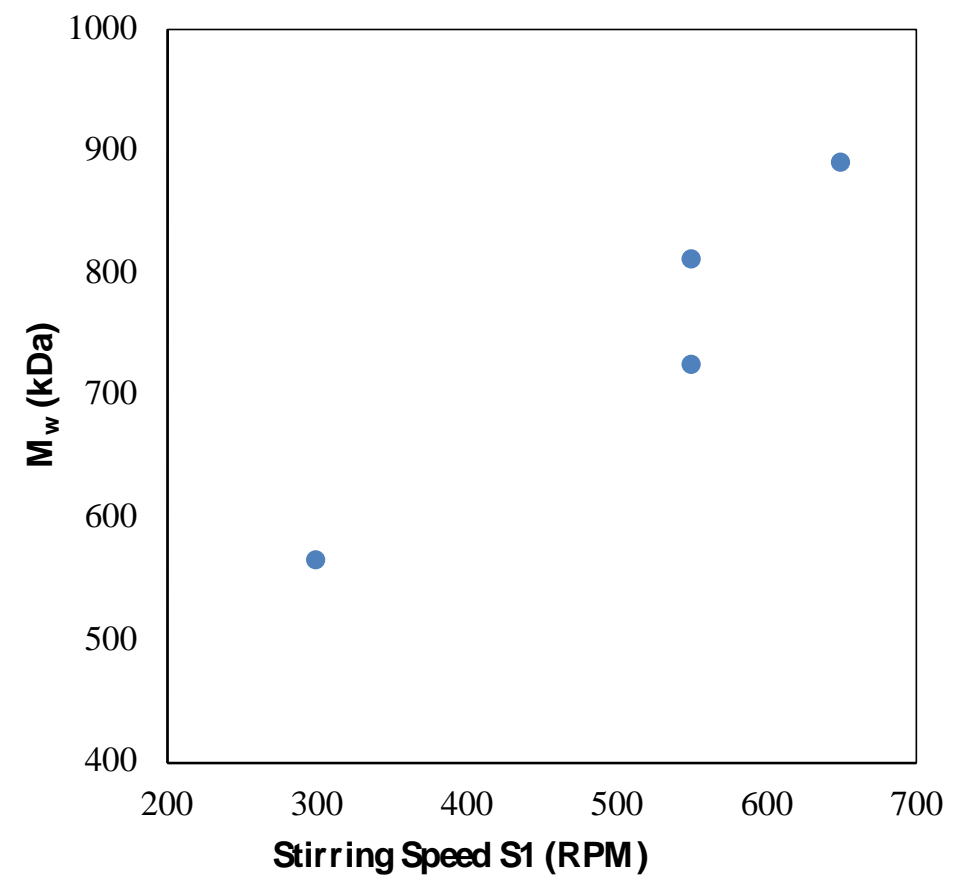

Figure 9. Evolution of $M_{\mathrm{w}}$ as a function of stirring speed for agitator system S1. Set point temperature $85^{\circ} \mathrm{C}$, initial pressure $8300 \mathrm{kPa}(83 \mathrm{bars})$. Experimental conditions: $1.5 \mathrm{~g} / \mathrm{L}$ of surfactant, $0.32 \mathrm{~g} / \mathrm{L}$ of KPS, $0.06 \mathrm{~g} / \mathrm{L}$ of buffer. No CTA.

In order to ensure that the rate of reaction is reasonably high but that the temperature is controllable, and to maintain the same conditions of mass transfer so as to be able to understand the impact of the other process parameters, in the following sections, it was decided to work under constant stirring rate depending on the agitation system used: In the experiments with agitator S1, we chose to work at a stirring rate of $550 \mathrm{rpm}$, and with S2 at an agitation rate of 400 rpm, unless otherwise stated.

\subsection{Process parameters and particle growth}

In ideal free radical polymerisations, it is usually assumed that the chain transfer agent controls the molecular weight of the produced polymer without affecting the rate of polymerisation. This is based on the implicit assumption that free radicals created by a chain transfer event to CTA have essentially the same reactivity as free radicals created by the reaction of an initiator fragment and the monomer. However, as discussed by Monteiro et al. ${ }^{[10]}$, ethyl acetate, the CTA used in this work (and presumably most compounds containing a labile hydrogen), shows a degradative effect on the polymerisation rate. A series of batch and semi-batch experiments were run to investigate this effect. The different species concentrations remained at the reference values, except for that of the EA (CTA), which was varied from 0 to $13.5 \mathrm{~g} / \mathrm{L}$. The recipes are 
given in Table 2. Note that batch reactions were done with agitator setup S1 at $550 \mathrm{rpm}$, while semi-batch polymerisations were done with S2 at $400 \mathrm{rpm}$.

Table 2. Recipes of the batch (R16, R17, 19, R20) and semi-batch (S11, S12, S20) polymerisations performed at different concentrations of EA. Batch reactions done with agitator setup S1 at $550 \mathrm{rpm}$. Semi-batch polymerisations done with S2 at $400 \mathrm{rpm}$.

\begin{tabular}{|c|c|c|c|c|c|}
\hline Run & $\begin{array}{c}\text { Surfactant } \\
\left(\mathbf{g} \cdot \mathbf{L}_{\text {water }}^{-1}\right)\end{array}$ & $\begin{array}{c}\text { KPS } \\
\left(\mathrm{g} \cdot \mathbf{L}_{\text {water }}^{-1}\right)\end{array}$ & $\begin{array}{c}\text { Salt } \\
\left(\mathbf{g} \cdot \mathbf{L}_{\text {water }}^{-1}\right)\end{array}$ & $\begin{array}{c}\mathbf{E A} \\
\left(\mathbf{g} \cdot \mathbf{L}_{\text {water }}^{-1}\right)\end{array}$ & $\begin{array}{c}\text { Wax } \\
(\mathrm{g}) \\
\end{array}$ \\
\hline \multicolumn{6}{|c|}{ Batch polymerisations } \\
\hline$R 16$ & 1.5 & 0.09 & 0.06 & 0.0 & 2.4 \\
\hline$R 17$ & 1.6 & 0.09 & 0.06 & 13.5 & 2.3 \\
\hline$R 19$ & 1.5 & 0.09 & 0.06 & 6.8 & 2.3 \\
\hline$R 20$ & 1.5 & 0.09 & 0.06 & 3.3 & 1.9 \\
\hline \multicolumn{6}{|c|}{ Semi-batch polymerisations } \\
\hline$S 11$ & 1.4 & 0.09 & 0.06 & 6.9 & 3.0 \\
\hline$S 12$ & 1.4 & 0.09 & 0.06 & 13.2 & 2.2 \\
\hline$S 20$ & 1.5 & 0.09 & 0.06 & 3.3 & 2.3 \\
\hline$S 10^{*}$ & 1.4 & 0.09 & 0.06 & 3.3 & 2.5 \\
\hline
\end{tabular}

*reproducibility test

The rate of polymerisation is plotted as a function of the solids content (SC, i.e. the weight fraction of polymer per unit volume of latex) in Figure 10. One can see the impact of the level of EA on the polymerisation, as well as that of the agitation system. The degradative effect of ethyl acetate on the reaction rate discussed by Monteiro et al. ${ }^{[10]}$ is observed in both batch and semibatch reactions. The slope of $R$ p slightly tends to decrease with the increase of the concentration of CTA, but it remains positive. As batch reactions were done with agitator setup S1 (at 550 $\mathrm{rpm}$ ), while semi-batch polymerisations were done with $\mathrm{S} 2$ (at $400 \mathrm{rpm}$ ), a higher reaction rate is obtained in semi-batch experiments since the beginning of the reaction 

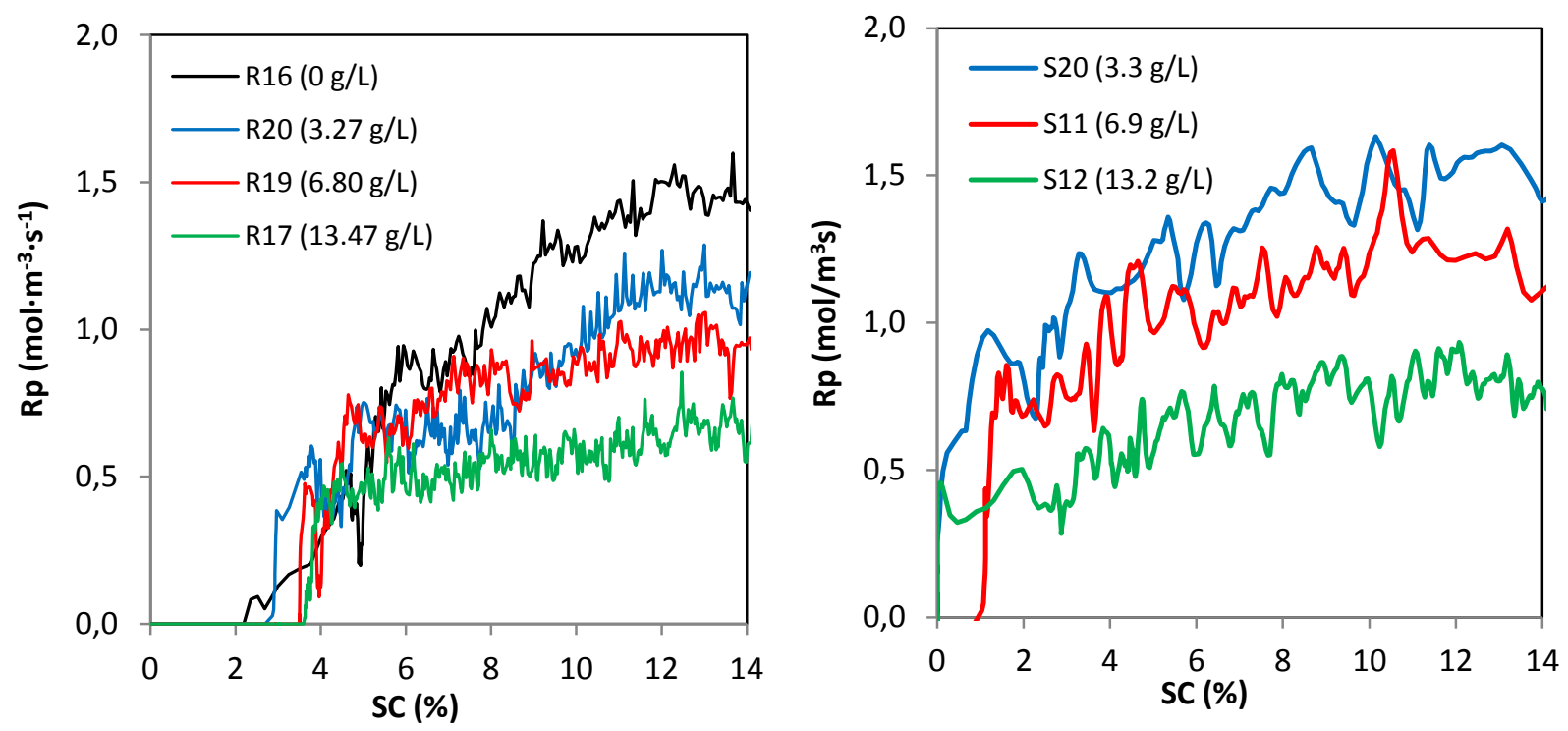

Figure 10. Effect of different levels of ethyl acetate on the rate of polymerisation of VDF in (a) batch polymerisations (adapted from reference [10]) and (b) semi-batch polymerisations.

It is useful to take a quick look at the impact of the amount of surfactant added to the reactor. First of all, as the amount of surfactant used is significantly lower than the CMC, homogeneous coagulative nucleation is the only possible means of forming particles. As one would expect, increasing the surfactant concentration leads to a higher polymerisation rate in the batch and semi-batch experiments as shown in Figure 11. It is interesting to note that regardless of the surfactant concentration used, the rate of polymerization remains constant in the batch experiments in Figure 11a, and continues to increase during this initial phase of the semibtach polymerizations in Figure 11b. All of the experiments show a very rapid increase in the rate at the beginning of the experiment, followed by a more gentle phase afterwards. This is true for both batch and semi-btach experiments. However the increase in the batch experiments is less remarkable, undoubtedly because the monomer concentration decreases monotonically (see above.) At constant pressure, the rate continues to increase. Since the rate of this type of nucleation depends on the monomer, initiator, and surfactant concentrations in the aqueous phase, there is no reason for this process to not continue throughout the entire polymerization if these quantities do not change. This is true of the monomer and (more or less) initiator concentrations. These results suggest that the homogenous-coagualtive nucelation mechansim by which the particles are formed continues throughout the polymerisation, and that surfactant concentrations as low as $0.75 \mathrm{~g} / \mathrm{L}$ are enough to stabilise the latex at least to a solids content of $15 \mathrm{wt} \%$. However the free surfactant levels will diminish as polymer accumulates in the reactor, meaning that we can stabilize more particles earlier in the polymerization than we can at the later stages. 



Figure 11. Impact of the surfactant concentration on the evolution of the polymerisation rate. (left) Batch polymerizations (using S1); (right) semi-batch polymerizations (using S2)

The impact of the amount of initiator injected in semi-batch polymerisations can be seen in Figure 12. Again, as expected an increased initial concentration of initiator leads to an increased rate of polymerisation. Also, as with the surfactant experiments presented in Figure 11, the rate of polymerisation continues to increase monotonically right after a very rapid increase in the rate at the start of the polymerisation.

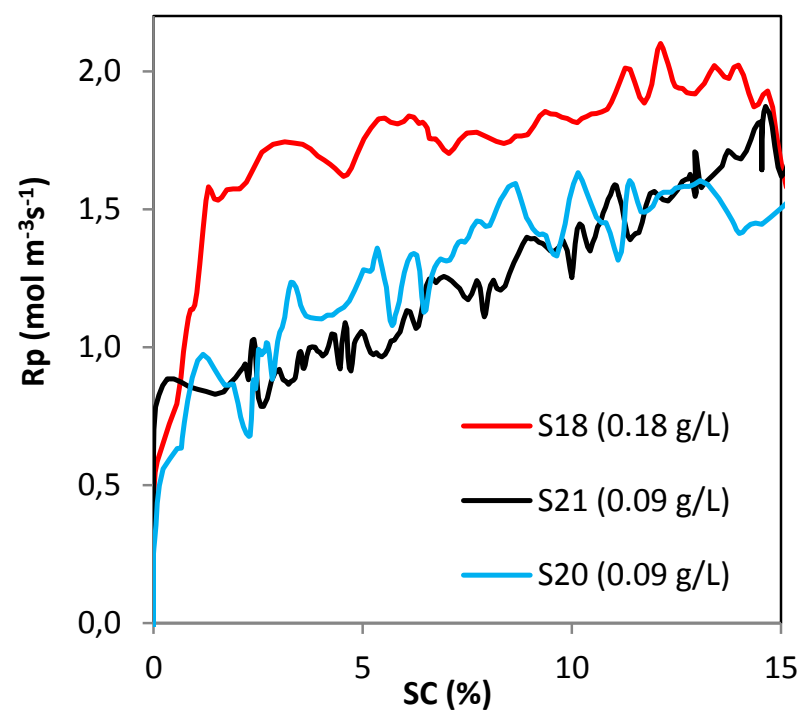


Figure 12. Impact of the injection protocol of initiator on the semi-batch polymerisation rate as a function of the solids content. Experimental conditions: $1.5 \mathrm{~g} / \mathrm{L}$ of surfactant, $0.06 \mathrm{~g} / \mathrm{L}$ of buffer, $3.2 \mathrm{~g} / \mathrm{L}$ of EA.

\section{Conclusions}

In the experiments presented in this work, all particles are generated by homogeneous coagulative nucleation since the quantity of surfactant used is lower than the CMC. The first step in this process is the growth and precipitation of oligo-radicals/dissolved chains in water. The rate of growth is a direct function of the availability of monomer in the aqueous phase, which in turn will depend on the pressure, temperature and the monomer solubility, as well as on the rate of agitation. The results show that the agitation rate has a strong impact on the initial rate of polymerisation, and on the ability to control the reactor temperature. It was shown that agitation conditions that lead to a high gas-liquid mass transfer coefficient also lead to higher rates of polymerization, and higher average molecular weights. This is most likely due to a greater availability of monomer for both the particle nucleation process, and possibly the propagation step in the polymer particles. As expected, the quantity of surfactant used has an impact on the initial rate of polymerization as well as it is expected that this will lead to a higher number of particles. From the continuous increase of the reaction rate with time, it may be deduced that particle nucleation continues, but certainly in parallel to continuous particle coagulation.

\section{ACKNOWLEDGEMENTS}

The authors are grateful for financial support by ANR Scale-up project (ANR-12-RMNP-0016).

\section{REFERENCES}

[1] A. C. Mendez Ecoscia, N. Sheibat-Othman, T. F. L. McKenna, Can. J. Chem. Eng., 2019, 97, 207.

[2] P. A. Charpentier, J. M. DeSimone, G.W. Roberts, Ind. Eng. Chem. Res., 2000, 39, 4588.

[3] M.K. Saraf, S. Gerard, L. M. Wojcinski, P. A. Charpentier, J. M. DeSimone, G. W. Roberts, Macromol. 2002, 35, 7976.

[4] T. S. Ahmed, J. M. DeSimone, G. W. Roberts, Chem. Eng. Sci., 2010, 65, 651.

[5] P. A. Mueller, G. Storti, M. Morbidelli, M. Apostolo, R. Martin, R., Macromol., 2005, 38, 7150.

[6] L. I. Costa, G. Storti, M. Morbidelli, A. Galia, G. Filardo, Polym. Eng. Sci., 2011, 51, 2093.

[7] M. Apostolo, V. Arcella, G. Storti, M. Morbidelli, Macromol., 1999, 32, 989. 
[8] H. Kaspar, K. Hintzer, K. D. Weilandt, J. Krichel, E. Peters, L. P. Chen, US6861490B2, 2005.

[9] M. P. Greuel, W. M. Grootaert, US5623038A, 1997.

[10] I. Stefanichen Monteiro, A. C. Mendez Ecoscia, T. F. L. McKenna, Ind. Eng. Chem. Res., 2019, 58, 20976.

[11] A.C. Mendez Ecoscia, N. Sheibat-Othman, T. F. L. McKenna, Macromol Symp., 2016, 320, 75.

[12] P. Pladis, A. H. Alexopoulos, J. Bousquet, C. Kiparissides, Computer Aided Chemical Engineering, 2005, 20, 319.

[13] P. Kappler, V. Gauthe, US7045584B2, 2006.

[14] S. Musio, M. Malvasi, V. Kapelyushko, US20180230245 A1, 2018.

[15] J. Blaise, E. Grimaud, US4025709 A, 1977.

[16] G. Brinati, V. Arcella, M. Albano, US 5583190A, 1996.

[17] S. Kobayashi, J. Hoshikawa, K. Kato, H. Kamiya, H. Hirai, US6646078 B2, 2003.

[18] T. Pascal, US20030225208, 2003.

[19] H. Wakamori, F. Suzuki, K. Horie, US5344904A, 1994.

[20] X. Bacque; P. Lasson, US5095081, 1992.

[21] M. Manikowski, S. Bodemeier, A. Lübbert, A. Bujalski, A. W. Nienow, Can. J. Chem. Eng., 1994, 72, 769.

[22] R. V. Chaudhari, R. V. Gholap, G. Emig, H. Hofmann, Can. J. Chem. Eng., 1987, 65, 744.

[23] E. Dietrich, C. Mathieu, H. Delmas, J. Jenck, Chem. Eng. Sci., 1992, 47, 3597.

[24] M. Teramoto, S. Tai, K. Nishii, H. Teranishi, Chem. Eng. J., 1974, 8, 223.

[25] S. Ledakowiczt, H. Nettelhoff, W.-D. Deckwer, Ind. Eng. Chem. Fundam. 1984, 23, 510. 